\title{
Modification of the Network-MT method and its first application in imaging the deep conductivity structure beneath the Kii Peninsula, southwestern Japan
}

\author{
Satoru Yamaguchi ${ }^{1}$, Makoto Uyeshima ${ }^{2}$, Hideki Murakami ${ }^{3}$, Sirou Sutoh ${ }^{4}$, Daichi Tanigawa ${ }^{4}$, Tsutomu Ogawa ${ }^{2}$, \\ Naoto Oshiman $^{5}$, Ryokei Yoshimura ${ }^{5}$, Koki Aizawa ${ }^{5 *}$, Ichiro Shiozaki ${ }^{6}$, and Takafumi Kasaya ${ }^{7}$ \\ ${ }^{1}$ Department of Earth and Planetary Sciences, Graduate School of Science, Kobe University, Nada, Kobe 657-8501, Japan \\ ${ }^{2}$ Earthquake Research Institute, University of Tokyo, 1-1-1 Yayoi, Bunkyo, Tokyo 113-0032, Japan \\ ${ }^{3}$ Research and Education Faculty, Kochi University, Kochi 780-8520, Japan \\ ${ }^{4}$ Graduate School of Science and Technology, Kobe University, Nada, Kobe 657-8501, Japan \\ ${ }^{5}$ Disaster Prevention Research Institute, Kyoto University, Uji, Kyoto 611-0011, Japan \\ ${ }^{6}$ Department of Management of Social Systems and Civil Engineering, Graduate School of Engineering, \\ Tottori University, Tottori 680-8552, Japan \\ ${ }^{7}$ Japan Agency for Marine-Earth Science and Technology, 2-15, Natsushima-cho, Yokosuka-shi 237-0061, Japan
}

(Received November 28, 2008; Revised May 14, 2009; Accepted May 14, 2009; Online published October 19, 2009)

\begin{abstract}
The Network-Magnetotelluric (NMT) method is well-suited for investigating deep and large-scale conductivity structure; however, application of the method is strongly dependent on the availability of telecommunication facilities (specifically, metallic transmission cables). To overcome the problem posed by the progressive replacement of metallic transmission cables with fiber cables, we developed a modified NMT (modified NMT) method consisting of purpose-built electrodes, making use of local metallic telecommunication lines, without a transmission cable. We first applied this modified NMT method over the Kii Peninsula, southwestern Japan, undertaking two-dimensional conductivity modeling along a transect across the central part of the peninsula. The model is characterized by a large $(\sim 20 \mathrm{~km}$ wide and depths of $10-60 \mathrm{~km})$ and highly conductive $(<10 \Omega \mathrm{m})$ zone in the central part of the peninsula between the Conrad discontinuity and the upper surface of the Philippine Sea slab. This zone contains the hypocenters of many deep low-frequency tremors but regular earthquakes are rare. The zone also corresponds to a high $-V_{p} / V_{s}$ area. The presence of fluid in the zone plays a key role in the absence of regular earthquakes, occurrence of deep low-frequency tremors, and elevated $V_{p} / V_{s}$ values, as well as enhancing conductivity.
\end{abstract}

Key words: Network-MT, deep low-frequency tremor, Kii Peninsula, Philippine Sea plate, electrical conductivity, telephone-line network, conductive zone.

\section{Introduction}

Among the various magnetotelluric (MT) methods available, the Network-MT method (NMT) (Uyeshima et al., 2001) is well-suited for determining regional electrical structure down to mantle depths. This method originally made use of earthing facilities installed for telecommunication equipments and metallic transmission cables (trunk telephone cables that connect pairs of telephone stations) for measuring voltage differences with a long dipole length of several tens of kilometers; however, this method has become unfeasible in most areas because metallic transmission cables have been almost completely replaced with optical fiber cables as part of the upgrading of telecommunication networks. To overcome this problem, we modified the NMT (we named it a modified NMT) method using

*Present address: Earthquake Research Institute, University of Tokyo, 1-1-1 Yayoi, Bunkyo, Tokyo 113-0032, Japan.

Copyright (c) The Society of Geomagnetism and Earth, Planetary and Space Sciences (SGEPSS); The Seismological Society of Japan; The Volcanological Society of Japan; The Geodetic Society of Japan; The Japanese Society for Planetary Sciences; TERRAPUB purpose-built electrodes and local metallic lines, without a transmission cable. We applied the modified NMT method, for the first time, to investigate the detailed features of the deep conductivity structure beneath the Kii Peninsula, central part of southwestern Japan (SWJ; Fig. 1(a)). Fuji-ta et al. (1997) have performed an ordinary wide-band MT investigation of regional conductivity structure beneath the Kii Peninsula. Thus, we can assess the validity of the newly developed modified NMT method by comparison. The new method also enables us to obtain the deeper levels of conductivity structure than in Fuji-ta et al.'s model.

Beneath SWJ, the Philippine Sea (PHS) plate is subducting along the Nankai Trough (Fig. 1(a)). Subcrustal earthquakes occur at depths of $30-140 \mathrm{~km}$ along the southern part of SWJ, defining a Wadati-Benioff zone with smallscale irregularities (Nakamura et al., 1997). In addition to mega-thrust earthquakes, deep low-frequency tremors (DLTs) have recently been recognized at the depth of the Moho beneath SWJ (Fig. 1(b)), occurring in a narrow zone along the strike of the arc (Obara, 2002). Two hypotheses have been proposed to explain the generation mechanism of the observed DLTs: fluid movement at depth (Obara, 2002; 
(a)

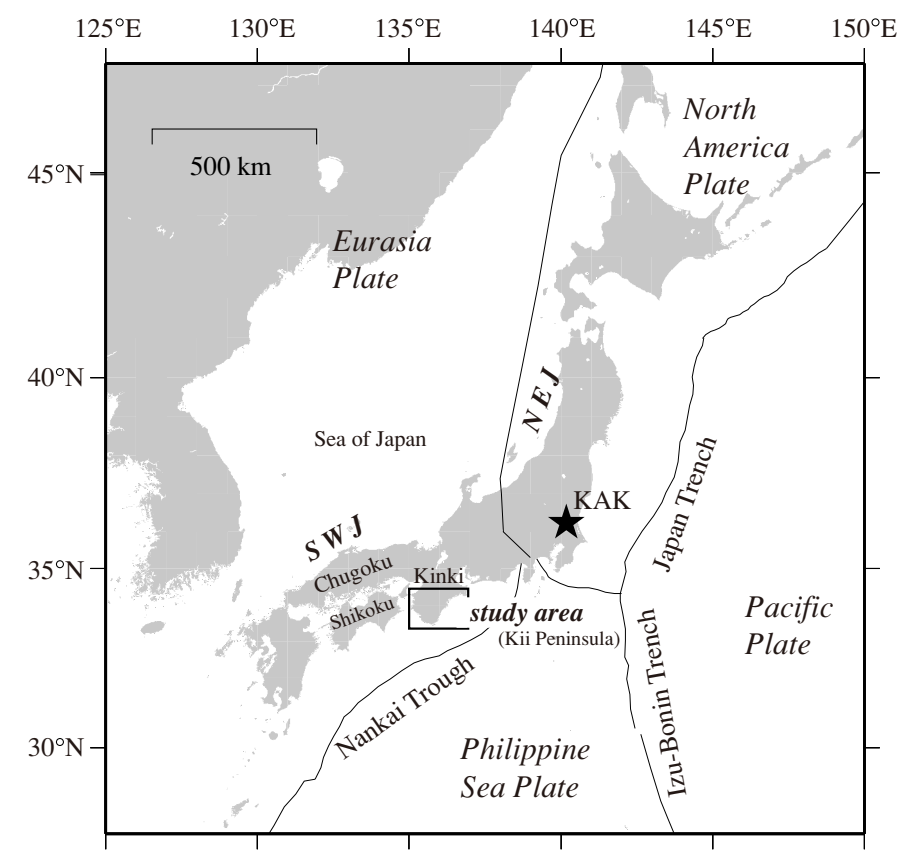

(b)

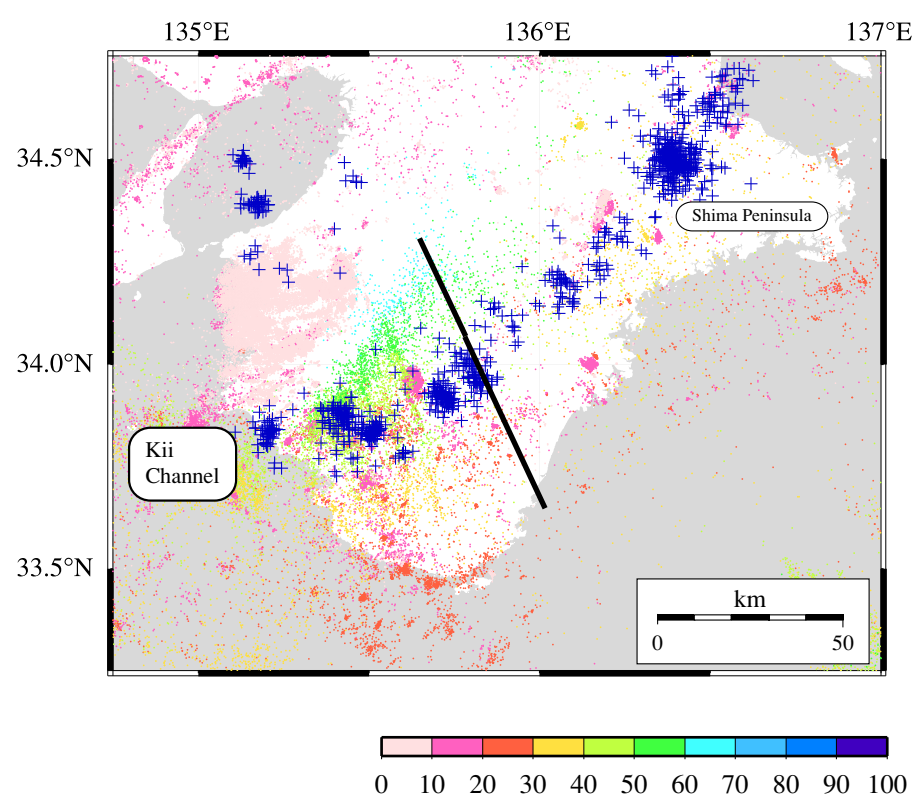

Hypocenter depth of the regular eathquakes $[\mathrm{km}]$

This color bar is not applied to the DLTs.

Fig. 1. Tectonic setting of the Japan region and distribution of epicenters beneath the Kii Peninsula. (a) The small rectangle shows the Kii Peninsula (the present study area). The star denotes the Kakioka geomagnetic observatory (KAK). Black lines indicate trenches, representing the major present-day plate boundaries. (b) Epicenters of regular earthquakes (colored dots) and DLTs (blue 'plus' symbols) beneath the Kii Peninsula for the period from October 1997 through December 2005. The thick line represents the transect employed for the 2-D conductivity model. Hypocenters were sourced from the integrated hypocenter database prepared by the Japan Meteorological Agency (Ueno et al., 2002).

Seno and Yamasaki, 2003) and slow slip upon the plate interface (Shelly et al., 2006).

Determination of the subsurface electrical conductivity structure can play a key role in revealing fluid distribution, because conductivity is sensitive to the amount of fluid and melt, their degree of connectivity, and the temperature and bulk composition of the host rock (e.g. Archie, 1942; Kariya and Shankland, 1983; Nesbitt, 1993; Glover et al., 2000). The MT method (Cagniard, 1953; Kaufman and Keller, 1981; Vozoff, 1991) is one of the most promising approaches in determining the nature of subsurface conductivity structures.

Fuji-ta et al. (1997) carried out a wide-band MT survey at eight sites along a NNW-SSE profile across the Kii Peninsula and presented a two-dimensional (2-D) conductivity model for the shallow-middle crust (up to $20 \mathrm{~km}$ in depth). Based on this model, the authors identified two upper-crustal anomalies: (1) a sub-horizontal conductive layer dipping to the northwest at depths of $5-10 \mathrm{~km}$ beneath the northern part of the transect, and (2) a resistive 
block at depths of $2-15 \mathrm{~km}$ beneath the southern part of the transect. Umeda et al. (2006) carried out a wide-band MT survey along an E-W transect across the southern part of the Kii Peninsula, and identified two conductors: one in the upper crust (3-7 km depth) and another in the lower crust (25-35 km depth). Another wide-band MT investigation was undertaken at six sites along a NW-SE transect across the Kii Peninsula resulting in the recovery of a 2-D conductivity model to a depth of $30 \mathrm{~km}$ (Uehara et al., 2005). Kasaya et al. (2005) carried out land and marine MT surveys in the area of the Kii Peninsula, and constructed a 2-D conductivity model in which the PHS slab is a resistive region. Their model delineated a conductivity structure down to $\sim 100 \mathrm{~km}$ depth, based on data with a period range of $10^{2}-10^{4} \mathrm{~s}$. Despite the advances made in these studies, the deep regional conductivity structure beneath the Kii Peninsula, especially around the hypocentral area of the DLTs, has yet to be established because of limitations in the observed period ranges (Fuji-ta et al., 1997; Uehara et al., 2005), locations of the transect (Umeda et al., 2006), and the limited number of onland observation sites (Kasaya et al., 2005).

Because the modified NMT observations undertaken in the present study were located over the southern part of the Kii Peninsula (south of the Median Tectonic Line), it would be possible to construct a three-dimensional (3-D) conductivity model beneath the entire peninsula; however, we consider that, as a first analysis, it would be better to concentrate on the transect along which the conductivity models were obtained, and along which other geophysical features are clearly imaged, in order to assess the validity of the new method. Therefore, we constructed a 2-D conductivity model along a transect across the central part of the Kii Peninsula (Fig. 1(b)). The location of the transect was selected based on the following three factors: (1) the transect crosses the largest cluster of DLT epicenters beneath the peninsula; (2) the transect is considered the most suitable for 2-D modeling beneath the peninsula because it is distant from both the western coast line, which is sub-parallel to the transect, and from the Shima Peninsula, which extends from the Kii Peninsula to the east (Fig. 1(b)); and (3) previous studies were located at similar locations, employing transects of similar orientations (e.g. Fuji-ta et al., 1997).

In this paper, we first introduce the technical aspects of the modified NMT method and related observations across the Kii Peninsula. Second, we discuss the obtained 2-D model, which is characterized by a highly conductive zone between the lower crust and the upper surface of the PHS slab. Finally, we seek to explain the enhanced conductivity within this zone and investigate the relationship between the obtained structure and subsurface seismic activity.

\section{Observations}

\subsection{Modification of the NMT method}

The NMT method was developed and first applied in central and eastern Hokkaido, northeastern Japan (NEJ), by Uyeshima (1990) and Uyeshima et al. (2001). Yamaguchi et al. (1999) and Satoh et al. (2001) applied the method in eastern Shikoku, SWJ, and eastern Hokkaido, NEJ, respec- tively. These observations made use of the earthing facilities installed at telephone stations and metallic transmission cables with a long dipole length of several tens of kilometers. The long electrode spacing means that the observed responses are relatively free from the effects of small-scale near-surface heterogeneities in conductivity, thereby enabling the measurement of voltage differences with a high signal-to-noise $(S / N)$ ratio.

However, almost all of the metallic transmission cables throughout Japan and probably elsewhere throughout the world have been recently replaced with optical fiber cables as part of the modernization of telecommunication networks. To overcome this problem, we developed the modified NMT method, which uses the local metallic lines that run between telephone stations and end-users within the region covered by each station (the region is called the local service area) as these metallic lines are still widely deployed in Japan. This method is based on similar research undertaken in small, specific areas with the aim of monitoring temporal variations in voltage differences arising from crustal activity (Uyeshima, 2007).

Figure 2 shows a sketch of the experimental design of the modified NMT system. Voltage differences are measured using the local metallic lines owned by NTT (Nippon Telegraph and Telephone Corporation), purpose-built $\mathrm{Pb}-\mathrm{PbCl}_{2}$ electrodes, and the earthing facilities of telephone stations, where data loggers are installed. The purpose-built electrodes are installed near the telephone poles to enable us to easily connect them to the telephone lines. In each local service area, three or four purpose-built electrodes were installed in such a way as to maximize the area within the polygon defined by the electrode points. We refer to each spatial unit of voltage-difference measurement in a given local service area as a "Net," with each Net consisting of a data logger, the earthing facilities of a telephone station, and purpose-built electrodes connected by metallic lines. For each Net, we identified one (or more) triangular or tetragonal region (termed "Areas") to be analyzed (e.g. the gray polygons in Fig. 2). Each Area was made as large as possible in order to reduce the effect of local near-surface heterogeneities and to cover the study area with few gaps. The location of each Area is represented by its center point, which we call the "Site," and which we refer to when the characteristic properties (e.g. MT response functions) of the Area are represented by a point.

Use of the modified NMT method yields two new advantages, (1) reduced levels of artificial noise, and (2) free arrangement of the dipole, while retaining three key advantages of the original NMT method: (3) high $S / N$ ratio, (4) reduced distortion effect, and (5) small risk of missing data due to factors such as cutting cables between electrodes.

Advantages (1) and (2) are obtained because we were able to select suitable telephone poles from among the many available in the study area. Advantages (3) and (4) are obtained by measuring voltage difference along a very long dipole, while (5) arises because the NTT lines are well maintained. There also exist two disadvantages in using the modified NMT method: (1) extra labor and cost is required to install the purpose-built electrodes, and (2) a lack of connections between telephone stations means that it is 


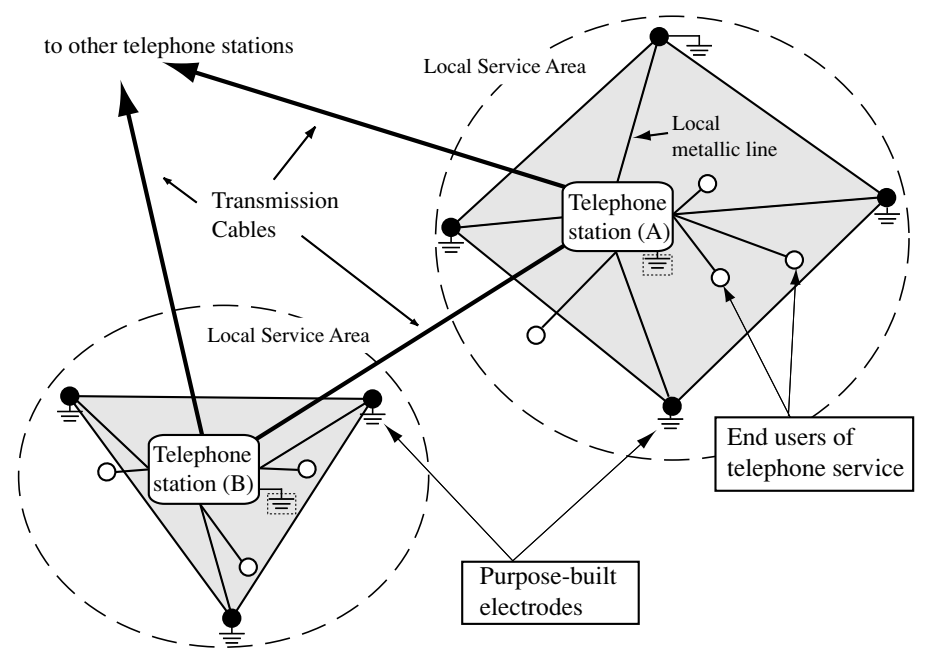

Fig. 2. A sketch of the experimental design of the modified NMT method. Local metallic lines and transmission cables are shown by thin and thick lines, respectively. All the local metallic lines from the end users of the telephone service in each local service area are connected to the telephone station. A data logger is installed at each telephone station. The gray polygons represent Areas, respectively.



Fig. 3. Spatial distribution of Nets throughout the Kii Peninsula. MT responses at dark blue Areas (Areas 1-5) were used to construct a 2-D conductivity model. In addition to these Areas, MT responses at light blue Areas between the dashed lines were used for G-B strike analysis. Other Areas are shown by gray triangular or tetragonal elements. The 2-D conductivity model was determined along the transect $\mathrm{A}-\mathrm{A}^{\prime}$. Areas marked by asterisks are regarded as being near the coast thereby being susceptible to three-dimensionality. The star indicates the temporary geomagnetic observation site (KII). The red, blue and green circles in each Net indicate the telephone satiation, the electrode points, and station center. Blue 'plus' symbols are the epicenters of DLTs (Ueno et al., 2002).

not always possible to obtain spatially continuous measurements of the electric field.

\subsection{Observations across the Kii Peninsula}

Here, we describe in detail the technical aspects of our observations. A brief summary of the observation method can be found in Kasaya et al. (2003). Prior to starting observations, we selected 54 telephone stations across the Kii
Peninsula that satisfied the following conditions: (1) large coverage area, (2) location far from the electric railway lines that run along the western coast of the peninsula, and (3) that together provide a near-uniform distribution over the study area. Candidate telephone poles were first selected upon a map. We then visited them to check that the poles were not located close to steep cliffs, large artificial struc- 
tures (e.g. tunnels, bridges, dams), sources of electric noise (e.g. high-voltage transmission lines, transformer substations), or densely inhabited areas. Ultimately, 192 electrode points were selected and used for measurements (Fig. 3).

Digital recorders (SES93, produced by AD Systems) were installed at each telephone station to record voltagedifference data. Analog signals were recorded in 20-bit binary format after anti-aliasing low-pass filtering. The range used was $\pm 10.5 \mathrm{~V}$, and the resolution was $0.02 \mathrm{mV}$. Data values were measured every $1 \mathrm{~s}$, with $10 \mathrm{~s}$ averages being stored in the data logger. These data were transferred to the laboratory daily using an acoustic modem.

Our observations ran from March 2002 to March 2004. Given the limited number of available instruments (e.g. data loggers, modems, and uninterruptible power supplies), we divided the study area into six sub-regions, each consisting of around 10 Nets. Approximately 3-6 months was required to complete recordings in each sub-region.

For magnetic field data, we used two horizontal components of geomagnetic data at two sites. The data at the first site were collected at $1 \mathrm{~s}$ intervals at the Kakioka Geomagnetic Observatory of the Japan Metrological Agency (KAK in Fig. 1(a)). The second comprised data recorded at $0.25 \mathrm{~s}$ intervals at a temporary station established upon the Kii Peninsula (KII, Fig. 3). Details of the measurements undertaken at the temporary station can be found in Kasaya et al. (2003). Both datasets were averaged to give time series at $10 \mathrm{~s}$ intervals, to match the sampling interval employed for voltage differences.

\section{Data Analysis}

\subsection{MT response functions}

To obtain MT response functions, we need electric field and magnetic field data for the Kii Peninsula; however, magnetic data at KII were only obtained from December 2002 to August 2003, with a period of several months for which no data were available because of equipment malfunctions. To overcome this problem, we estimated the response functions for each Area using a two-step process. In the first step, we calculated tentative MT response functions $\left(Z_{x x}, Z_{x y}, Z_{y x}\right.$, and $\left.Z_{y y}\right)$ between the electric field in each Area and the magnetic field at KAK (Eq. (1)), and calculated the inter-station transfer function (ISTF, expressed with $C, D, E$, and $F$ ) of the horizontal components (Eq. (2)). In the second step, these tentative MT response functions were corrected using the ISTF of the horizontal components (Eq. (3)).

$$
\begin{aligned}
& \left(\begin{array}{l}
E_{x} \\
E_{y}
\end{array}\right)=\left(\begin{array}{ll}
Z_{x x} & Z_{x y} \\
Z_{y x} & Z_{y y}
\end{array}\right)\left(\begin{array}{l}
H_{x}^{\mathrm{KAK}} \\
H_{y}^{\mathrm{KAK}}
\end{array}\right) \\
& \left(\begin{array}{l}
H_{x}^{\mathrm{KAK}} \\
H_{y}^{\mathrm{KAK}}
\end{array}\right)=\left(\begin{array}{ll}
C & D \\
E & F
\end{array}\right)\left(\begin{array}{l}
H_{x}^{\mathrm{KII}} \\
H_{y}^{\mathrm{KII}}
\end{array}\right) \\
& \left(\begin{array}{l}
E_{x} \\
E_{y}
\end{array}\right)=\left(\begin{array}{ll}
Z_{x x} & Z_{x y} \\
Z_{y x} & Z_{y y}
\end{array}\right)\left(\begin{array}{ll}
C & D \\
E & F
\end{array}\right)\left(\begin{array}{l}
H_{x}^{\mathrm{KII}} \\
H_{y}^{\mathrm{KII}}
\end{array}\right) \\
& \left(\begin{array}{ll}
Z_{x x}^{\prime} & Z_{x y}^{\prime} \\
Z_{y x}^{\prime} & Z_{y y}^{\prime}
\end{array}\right)=\left(\begin{array}{ll}
Z_{x x} & Z_{x y} \\
Z_{y x} & Z_{y y}
\end{array}\right)\left(\begin{array}{ll}
C & D \\
E & F
\end{array}\right)
\end{aligned}
$$

Here, $E_{x}$ and $E_{y}$ are the northward and eastward horizontal components of the electric field, respectively. $H_{x}^{\mathrm{KAK}}, H_{y}^{\mathrm{KAK}}$ and $H_{x}^{\mathrm{KII}}, H_{y}^{\mathrm{KII}}$ represent the northward and eastward horizontal components of the magnetic field at KAK and KII, respectively. $C$ and $D$ are complex transfer functions between the northward component of the magnetic field at KAK and the northward and eastward components of the magnetic field at KII, respectively. $E$ and $F$ are complex transfer functions between the eastward component at KAK and the northward and eastward components at KII, respectively. $Z_{x x}^{\prime}, Z_{x y}^{\prime}, Z_{y x}^{\prime}, Z_{y y}^{\prime}$, and in Eq. (4) are the MT responses required for our analysis.

We used the robust remote-reference magnetotelluric data-processing code (RRRMT; Chave et al., 1987; Chave and Thomson, 1989) to compute MT response functions for periods between 213 and 10240 s (213-13653 s in some Areas); the longest period is much larger than that obtained using the conventional MT method. We identified highquality MT response functions based on two criteria: (1) the multiple coherency between the electric field at the Kii Peninsula and the magnetic field at KAK is greater than 0.7 , and (2) the $95 \%$ error in the phase value of the MT response function is less than $5^{\circ}$ for the entire analysis period.

We applied these two criteria in analyzing the electric field data obtained at Areas 1 to 7 (Fig. 3). High-quality MT response functions were obtained by analyzing 24-hour data for 30 days at Areas 4 and 7, night-time data (3.55 hours) for 30 days at Areas 2 and 3, and night-time data for 50 days at Area 1. At Area 5, the MT response functions derived from the night-time data for 50 days satisfied the first criterion; however, the $95 \%$ error in the phase value of the MT response functions was between $5^{\circ}$ and $10^{\circ}$ for almost the entire period. Despite this limitation, we decided to use these MT response functions as being representative of Area 5. We chose datasets spanning 30 or 50 days whichever had the largest daily sum of $A_{\mathrm{p}}$-index (this is an index of the degree of disturbance of the geomagnetic field, with larger values indicating greater disturbance); this comprised the 30 or 50 largest daily sums of $A_{\mathrm{p}}$-index from the dataset spread over between 90 and 180 days. We were unable to obtain sufficient data to determine the stable MT response functions at Area 6 because of the large number of days for which data were unavailable.

The ISTF of the horizontal components was computed using RRRMT for a period range of 213-13653 s. We made five sub-datasets from a long-duration dataset of $\sim 1.5$ years. Each sub-dataset consists of 24-hour data for 27 days, and they were selected around the spring equinox, summer solstice, autumnal equinox, and winter solstice of 2003 , and the spring equinox of 2004, with the aim of minimizing the effect of seasonal variations.

Here, we briefly summarize the period-dependence of the ISTF. The amplitude of $C$ rises to a peak value $(\sim 1.25)$ at a period of $300 \mathrm{~s}$, and decreases to unity with increasing period (Fig. 4). The amplitude of $F$ shows a minimum value of $\sim 0.9$ at the shortest period of $213 \mathrm{~s}$, and gradually increases to unity with increasing period. The amplitudes of $D$ and $E$ are clearly smaller than those of $C$ and $F$, respectively. The phase value of $C$ shows a minimum value of $\sim-2^{\circ}$ at the shortest period, increasing to a peak value of $\sim 10^{\circ}$ at a period of $1000 \mathrm{~s}$, but decreasing again to $0^{\circ}$ with increasing period. The phase value of $F$ increases 
$\mathrm{C}$ and $\mathrm{F}$
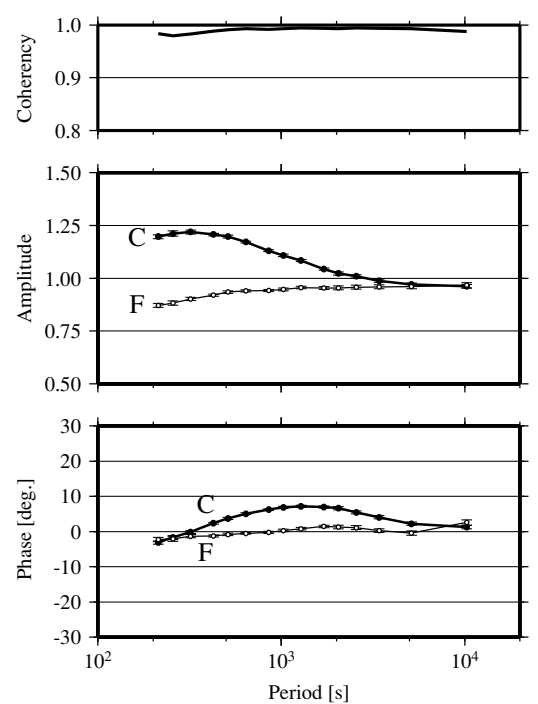

$\mathrm{D}$ and $\mathrm{E}$
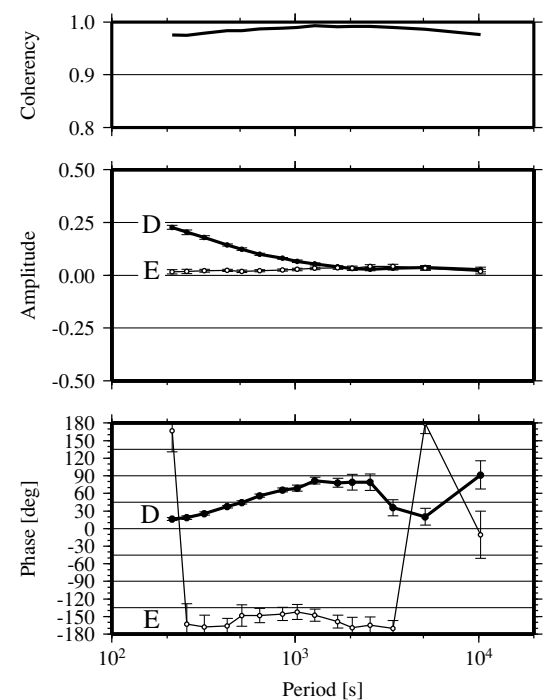

Fig. 4. Coherency, amplitude, and phase value of the inter-station transfer functions between station KAK and the temporary geomagnetic observation site located upon the Kii Peninsula (KII). $C-F$ are complex coefficients of the inter-station transfer functions. Details of the measurements performed at the temporal station can be found in Kasaya et al. (2003).

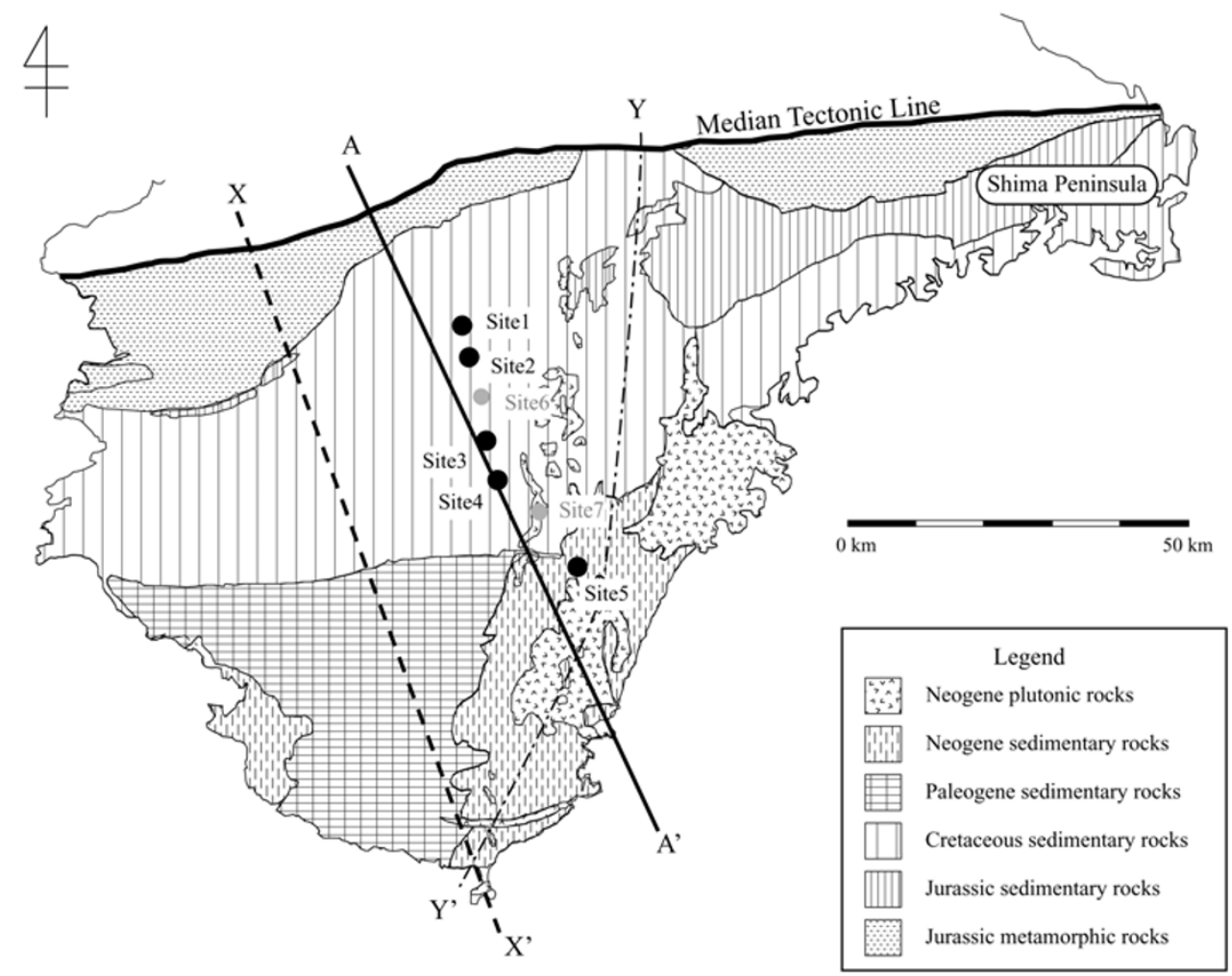

Fig. 5. Simplified geological map of the Kii Peninsula. The line A-A' shows the transect of the 2-D conductivity model. The dashed line $\mathrm{X}-\mathrm{X}^{\prime}$ shows the transect of the receiver function image (Yamauchi et al., 2003), and the dash-dot line $\mathrm{Y}_{-} \mathrm{Y}^{\prime}$ indicates the eastern boundary of the area in which high- ${ }^{3} \mathrm{He} /{ }^{4} \mathrm{He}$ well gas ( $>$ twice the air value of $1.4 \times 10^{-6}$ ) is observed (Matsumoto et al., 2003). Black and gray circles indicate the Sites used and not used for the 2-D analysis, respectively (see also Fig. 3). The map was redrawn from the seamless digital Geological Map of Japan (Geological Survey of Japan, AIST (ed.), 2007).

monotonously from $-2^{\circ}$ to $0^{\circ}$ with increasing period. Multiple coherencies show a sufficiently large value $(>0.95)$ throughout the entire period range.

\subsection{Distortion analysis}

The Kii Peninsula is dominated by two tectonic zones: the Shimanto belt (Paleogene-Neogene sedimentary rocks) and the Sambagawa belt (Jurassic metamorphic rocks). Both of these belts follow a $\mathrm{N} 80^{\circ} \mathrm{E}-\mathrm{S} 80^{\circ} \mathrm{W}$ trend, concor- 
(a) All Areas in the central part of the Kii Peninsula

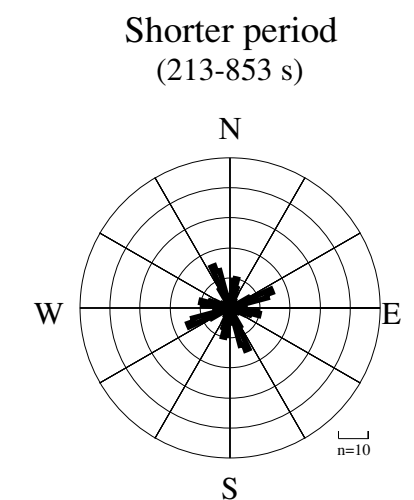

S

\section{Longer period} (1024-10240 s)

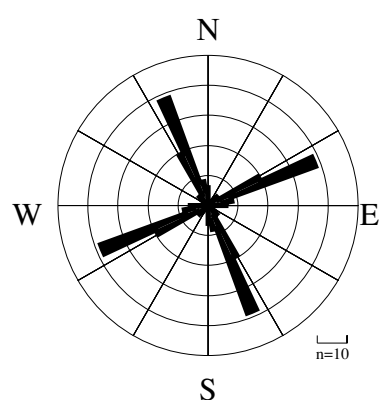

Total

(213-10240 s)

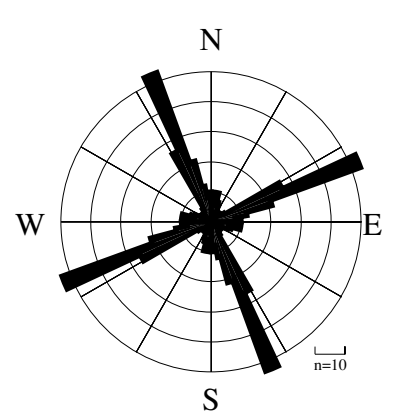

(b) Without those Areas located near the coast

\section{Shorter period \\ $(213-853 \mathrm{~s})$}

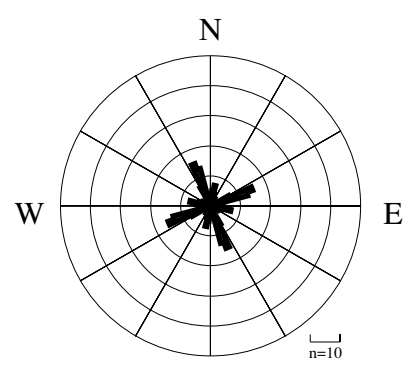

$\mathrm{S}$

Fig. 6. Rose diagrams of regional strikes after Groom-Bailey decomposition for Areas in the central part of Kii Peninsula. (a) Rose diagrams of the regional strike for Areas in the central part of the Kii Peninsula. The diagrams for the shorter-period range $(T<1000 \mathrm{~s})$, the longer-period range $(T>1000 \mathrm{~s})$, and entire period range are shown from left to right. Note that $\pi / 2$ ambiguities are also included in each diagram. (b) Rose diagram of the regional strike for the shorter-period range $(T<1000 \mathrm{~s})$ for all Areas for which MT responses were obtained, excluding the three Areas located near the coastline (Areas with asterisks in Fig. 3).

dant with the strike of the Nankai Trough (Figs. 1(a) and 5). The general trend of the Bouguer anomaly in this region (Shichi and Yamamoto, 2001) is also consistent with the geological trend. Therefore, we presume to interpret the data in terms of a regional 2-D structure overlain by local 3-D galvanic scatterers. However, Area 7 was found to be located within a region of igneous rocks (Fig. 5). The strike of the intrusion is nearly perpendicular to the general trend of geological units upon the Kii Peninsula, and the spatial scale of the Area is insufficient to cancel out the effect of this local heterogeneity. Accordingly, we ignore the results obtained at Area 7 in order to avoid strong 3-D effects on the conductivity model. We bear in mind that regional three-dimensionality may be recognized at sites near the coast in addition to the Area 7.

Using the Groom-Bailey (G-B) decomposition method (Groom and Bailey, 1989), we estimated the frequencydependent and site-dependent regional strike directions from the MT impedance tensors for those Areas located in the central part of the Kii Peninsula (Areas colored light and dark blue between the thin dashed lines in Fig. 3). Two peaks $\left(\mathrm{N} 25^{\circ} \mathrm{W}-\mathrm{S} 25^{\circ} \mathrm{E}\right.$ and $\left.\mathrm{N} 65^{\circ} \mathrm{E}-\mathrm{S} 65^{\circ} \mathrm{W}\right)$ are clearly dom- inant for periods below $1000 \mathrm{~s}$ (Fig. 6(a)); two small peaks are also observed $\left(\mathrm{N} 10^{\circ} \mathrm{E}-\mathrm{S} 10^{\circ} \mathrm{W}\right.$ and $\left.\mathrm{N} 80^{\circ} \mathrm{W}-\mathrm{S} 80^{\circ} \mathrm{E}\right)$. We also considered the short-period range, excluding the three Areas located near the coast (Fig. 6(b)). In this case, the dominance of the $\mathrm{N} 25^{\circ} \mathrm{W}-\mathrm{S} 25^{\circ} \mathrm{E}$ and $\mathrm{N} 65^{\circ} \mathrm{E}-\mathrm{S} 65^{\circ} \mathrm{W}$ peaks is much more pronounced than that in the left-hand panel in Fig. 6(a). These results indicate that the central part of the Kii Peninsula can be regarded as $2-\mathrm{D}$, while some threedimensionality effect are recognized in the coastal area, as expected. The regional strike was either $\mathrm{N} 25^{\circ} \mathrm{W}-\mathrm{S} 25^{\circ} \mathrm{E}$ or $\mathrm{N} 65^{\circ} \mathrm{E}-\mathrm{S} 65^{\circ} \mathrm{W}$, because of $\pi / 2$ ambiguity. Considering the general geological strike, the strike of the Nankai Trough, and the general trend of the Bouguer anomaly in the region, $\mathrm{N} 65^{\circ} \mathrm{E}-\mathrm{S} 65^{\circ} \mathrm{W}$ was chosen as the regional strike for our study area. We therefore fixed the regional strike to $\mathrm{N} 65^{\circ} \mathrm{E}-\mathrm{S} 65^{\circ} \mathrm{W}$ and again decomposed the data for all Areas with period-independent twist and shear.

After decomposing the distortion components, the MT response function of each Area is regarded as that of the relevant Site. Figure 7 shows the apparent resistivity and phase value of the TM mode at each Site. Both the apparent resistivity and phase values at the three northernmost Areas 


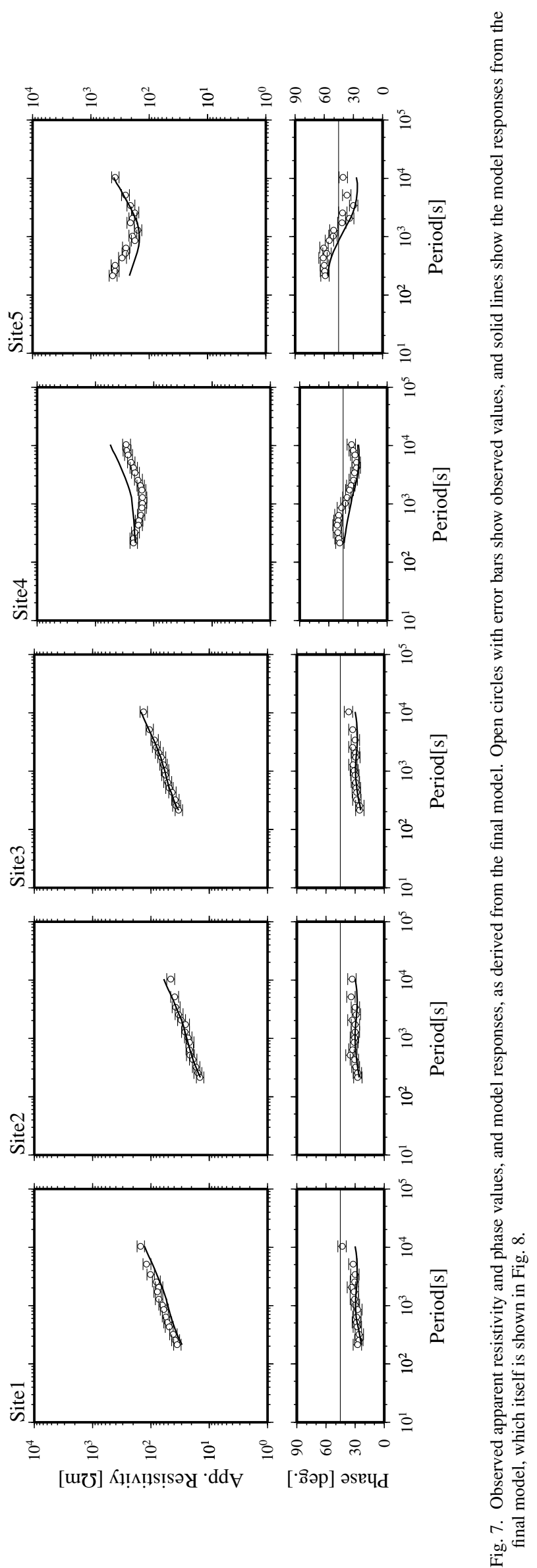


(Areas 1-3) increase with increasing period. The apparent resistivity at Area 2 is about half that at Areas 1 and 3. The phase values at Areas 1-3 are between $30^{\circ}$ and $40^{\circ}$. Plots of apparent resistivity at the two southernmost Areas (Areas 4 and 5) are concave, with minimum values of $\sim 150 \Omega \mathrm{m}$ at $\sim 10^{3} \mathrm{~s}$. The phase values at Areas 4 and 5 are $50^{\circ}$ and $60^{\circ}$, respectively, at the shortest period; with increasing period, the values decrease to $35^{\circ}$. The phase values at Areas 4 and 5 increase in the longest-period range. The observation of period-dependence of apparent resistivity and phase values at all Areas is consistent in terms of the existence of a causal relationship as indicated by Fischer et al. (1981).

\section{2-D Inversion and Conductivity Structure}

A 2-D geo-electrical cross-section was constructed along the transect $\left(\mathrm{N} 25^{\circ} \mathrm{W}-\mathrm{S} 25^{\circ} \mathrm{E}\right.$; A-A $\mathrm{A}^{\prime}$ in Figs. 3 and 5). Previous studies have noted that a 2-D analysis based on TM-mode data yields a reasonable conductivity structure, even though the regional conductivity structure may be 3-D (Wannamaker et al., 1984; Ledo et al., 2002; Siripunvaraporn et al., 2005). This argument is applicable to the present study area because three-dimensionality of the conductivity structure is recognized in the coastal region. Furthermore, Umeda et al. (2006) reported a N-S strike for the conductivity structure in the southern part of the Kii Peninsula, as obtained using the G-B method; their survey line crosses our transect at $\sim 5 \mathrm{~km}$ south of Site 5 , indicating the complexity of regional strike in the southernmost part of the peninsula. Consequently, we decided to perform a 2-D model analysis based on the TM-mode data.

In the 2-D inversion, the location of each Site was projected onto the transect. The Pacific Ocean was included by setting a fixed resistivity of $0.25 \Omega \mathrm{m}$ and known bathymetry along the transect. We inverted the apparent resistivity and phase value of TM-mode impedances with an assumed error floor of $15 \%$ in both apparent resistivity and phase, using the code proposed by Uchida (1993) and Uchida and Ogawa (1993). This code is designed to determine a smooth 2-D structure with the maximum Bayesian likelihood, based on Akaike's Bayesian information criterion (ABIC). After 20 iterations, the 10th iteration result, which has the minimal ABIC, was chosen as the most plausible model, hereafter referred to as the final model (Fig. 8). This model has a low overall root-mean-square (RMS) misfit of 1.66 .

Figure 7 compares the synthetic apparent resistivity and phase values obtained from the final model with observed values, revealing an acceptable overall fit. The model contains two characteristic conductive zones: one located beneath Site $4(\mathrm{C} 1)$, and another beneath the Pacific Ocean (C2). The model also contains three resistive zones: a northern resistor (R1) at depths of 20-40 km beneath Site 1; a small, shallow, central resistor (R2) beneath Sites 3 and 4; and a southern resistor (R3) beneath Site 5 .

In the modified NMT method, electric fields in each Area were computed by dividing the voltage difference by the electrode separation. Poll et al. (1989) noted that this procedure of computing the electric field gives the true value only if the field is uniform between the electrodes; therefore, we estimated the effect of non-uniformity in the elec-

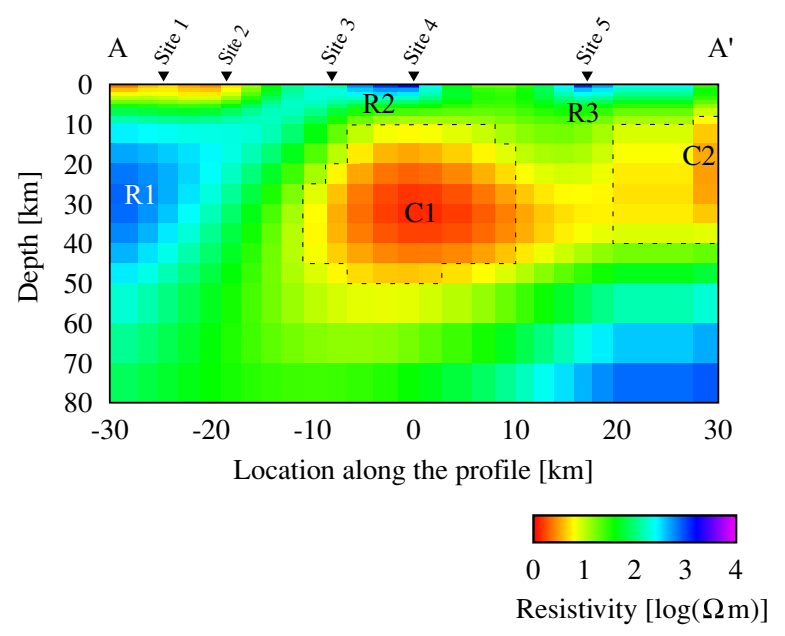

Fig. 8. Final 2-D geo-electric cross-section along the transect $\mathrm{A}-\mathrm{A}^{\prime}$. The zones $\mathrm{C} 1$ and $\mathrm{C} 2$, enclosed by dashed lines, show characteristic highly conductive regions; characteristic resistive zones are marked by R1, R2, and R3. Site locations are indicated along the top of the figure.

tric field between each pair of electrodes. First, the voltage difference was obtained by integrating the electric field values along the dipole, which was computed from the final model. Using this value, the mean impedance of the Area was then computed. Next, we compared the mean impedance with that calculated at the center of the Area. The two impedances agreed with each other within $1 \%$ for all the Areas and all the periods, indicating a negligible effect of non-uniformity in the electric field.

\section{Discussion}

Voltage-difference data along the dipole between the earthing facility of a telephone station and a purpose-built electrode have the potential to be contaminated by artificial noise, such as regular noise with a period much shorter than that of variations in the magnetic field, and irregular noise. Figure 9 shows an example of the voltage-difference record for Area 4, along with the magnetic field record at KAK. Figures $9(\mathrm{c}-\mathrm{e})$ show the records along the dipoles between electrodes No. 2 and No. 4 (Dipole 24), between electrode No. 2 and the earthing facility of the telephone station (Dipole 20), and between electrode No. 4 and the earthing facility of the telephone station (Dipole 40). The directions of the dipoles are $\mathrm{N} 71.5^{\circ} \mathrm{E}$ (Dipole 24 ), $\mathrm{N} 76.9^{\circ} \mathrm{E}$ (20), and $\mathrm{N} 57.3^{\circ} \mathrm{E}(40)$, and they are approximately parallel each other.

The common noise in the records along Dipoles 20 and 40 is not apparent in the record along Dipole 24, suggesting the location of the noise source is near the earthing facility of the telephone station. The noise may result from the use of electric devices in homes around the telephone station and/or electric flow from the telecommunication equipment located in the telephone station into the station's earthing facility. It is noteworthy that the temporal variation in voltage difference along Dipole 24 shows a strong correspondence to variations in the magnetic field. To undertake a qualitative evaluation, we calculated the complex response function $\left(V_{N}, V_{P}\right)$ between temporal variations in voltage difference which have been normalized by the dipole length along 
(a)

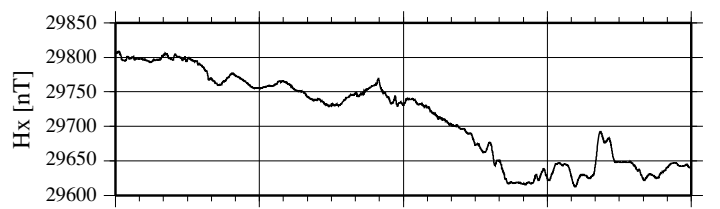

(b)

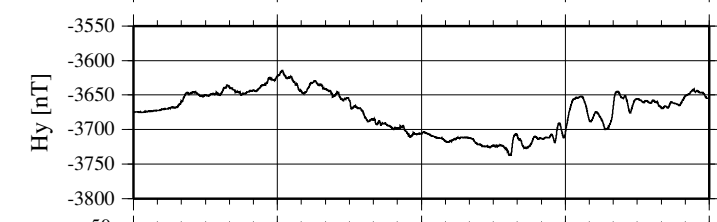

(c)

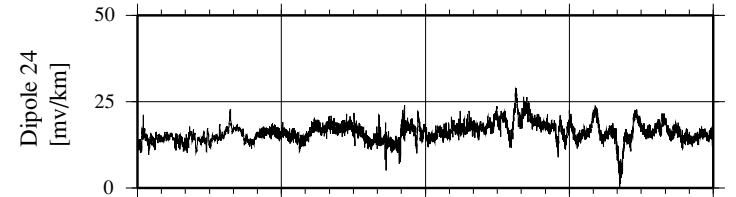

(d)

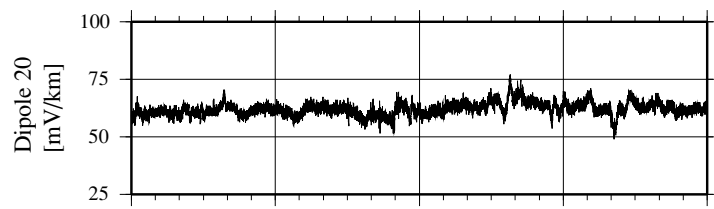

(e)

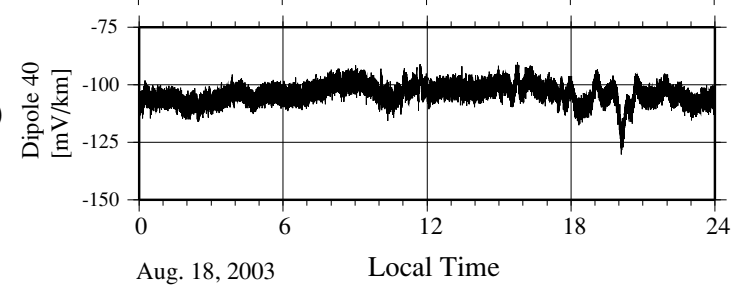

Fig. 9. Example of the voltage-difference record upon the Kii Peninsula and the magnetic field record at KAK. (a) and (b) indicate the northward and eastward horizontal components of the magnetic field at KAK, respectively. (c), (d) and (e) indicate the voltage-difference record along Dipoles 24, 40, and 40, respectively. The vertical scale used in (c) is exaggerated by twice as much as that in (d) and (e) in order to enable comparisons between magnetic field variations and voltage difference. Electrode No. 2 is installed $4.2 \mathrm{~km}$ from the telephone station toward N76. $9^{\circ}$, and electrode No. 4 is installed $1.63 \mathrm{~km}$ from the telephone station toward $\mathrm{N} 237.3^{\circ}$.

each dipole and two horizontal components of the magnetic field between the period range of 213 and 10,240 s for 24hour data collected over 3 days:

$$
V=V_{N}^{*} H_{N}+V_{P}^{*} H_{P}
$$

where $H_{N}$ and $H_{P}$ are the normal and parallel components of the horizontal magnetic field to each dipole at KAK, respectively. The estimation error of $V_{N}$ for Dipole 24 is an average of $68 \%$ less than that for Dipole 20 (the minimum value is $27 \%$ less), and an average of $24 \%$ less than that for Dipole 40 (the minimum value is $7.7 \%$ less). We therefore conclude that the use of purpose-built electrodes and local metallic lines is effective in reducing artificial noise in the electric field data, enabling us to obtain high-quality MT response functions.

The final model and the model proposed by Fuji-ta et al. (1997) share a number of common features: (1) a shallow resistive zone beneath the southernmost part of the trnsection where Neogene plutonic rocks are exposed, (2) a conductive zone beneath the central part of the Kii Peninsula below $20 \mathrm{~km}$ depth, and (3) a shallow conductive zone to the north of this conductive zone. The shallow resistor beneath
Sites 3 and 4 is not recognized in Fuji-ta et al.'s model, and resister R3 is only weakly apparent; however, these discrepancies are relatively minor given the fact that Fuji-ta et al.'s model was constructed from the MT responses of a higherfrequency band than that employed in the present study and that Fuji-ta et al.'s model transect was oblique to ours by $\sim 30^{\circ}$. Therefore, we conclude that the final model and Fujita et al.'s model are consistent with each other, indicating in turn the reliability of the final model constructed from data obtained using the newly developed modified NMT method.

The phase value of the period range below $1000 \mathrm{~s}$ at Site 4 and the apparent resistivity of the period range below $1000 \mathrm{~s}$ at Site 5, as calculated from the final model, appear to be inconsistent with observed values (Fig. 7). This discrepancy is probably caused by the presence of locally complex structures at shallow depths below the two sites. Such a structure cannot be recovered by the employed inversion scheme because the scheme is characterized by a smoothness constraint in resistivity distribution and because the resistivity model was calculated from the MT responses of the longperiod range (>213 s). Furthermore, Fuji-ta et al. (1997) proposed that a shallow conductive layer exists near Site 4; consequently, a local heterogeneity in resistivity is expected in this area.

This idea was tested by adding conductivity structures to the final model. We found that a simple two-layer block, consisting of a highly resistive layer upon a conductive layer, located below Sites 4 and 5 led to an improved fit between the model and observed responses (Fig. 10). Below Site 4, a shallow resistor $(50,000 \Omega \mathrm{m}$ at depths of $50 \mathrm{~m}$ to $1 \mathrm{~km}$, and $4.3 \mathrm{~km}$ wide) overlies a conductor ( $10 \Omega \mathrm{m}$ at depths between 1 and $3 \mathrm{~km}$, and $4.3 \mathrm{~km}$ wide). Below Site 5 , a shallow resistor $(50,000 \Omega \mathrm{m}$ at depths of $50 \mathrm{~m}$ to $1 \mathrm{~km}$, and $3.85 \mathrm{~km}$ wide) overlies a conductor ( $100 \Omega \mathrm{m}$ at depths between 1 and $3 \mathrm{~km}$, and $3.85 \mathrm{~km}$ wide). We also added a two-layer block below the entire area between Sites 4 and 5 ; however, this did not result in an improved fit. It is noteworthy that the addition of a common structure beneath the two sites leads to an improved fit. The acquisition of data over the short period range employed in this study would improve the resolution of the shallower conductivity structure, therefore enhancing the present discussion.

We found a highly conductive $(<10 \Omega \mathrm{m})$ zone beneath the central part of transect $A-\mathrm{A}^{\prime}$ at depths of $10-60 \mathrm{~km}$. In interpreting such features of the obtained conductivity model, it is useful to compare them with the results of seismological studies. Yamauchi et al. (2003) imaged seismicvelocity discontinuities in the crust and uppermost mantle beneath SWJ based on a receiver function analysis. They showed that the upper surface of the PHS slab is located at depths of $\sim 30$ and $\sim 60 \mathrm{~km}$ beneath the southern tip of the Kii Peninsula and northern end of our transect, respectively. The Conrad discontinuity lies at a depth of $\sim 20 \mathrm{~km}$ beneath the Kii Peninsula; thus, the highly conductive zone $\mathrm{C} 1$ is mainly located between the top of the lower crust and the upper surface of the PHS slab (Fig. 11). On the conductivity model, we also overlaid hypocenters located within $10 \mathrm{~km}$ either side of the transect. Earthquake hypocenters from October 1997 through December 2005 were selected from the integrated hypocenter database prepared by the Japan 

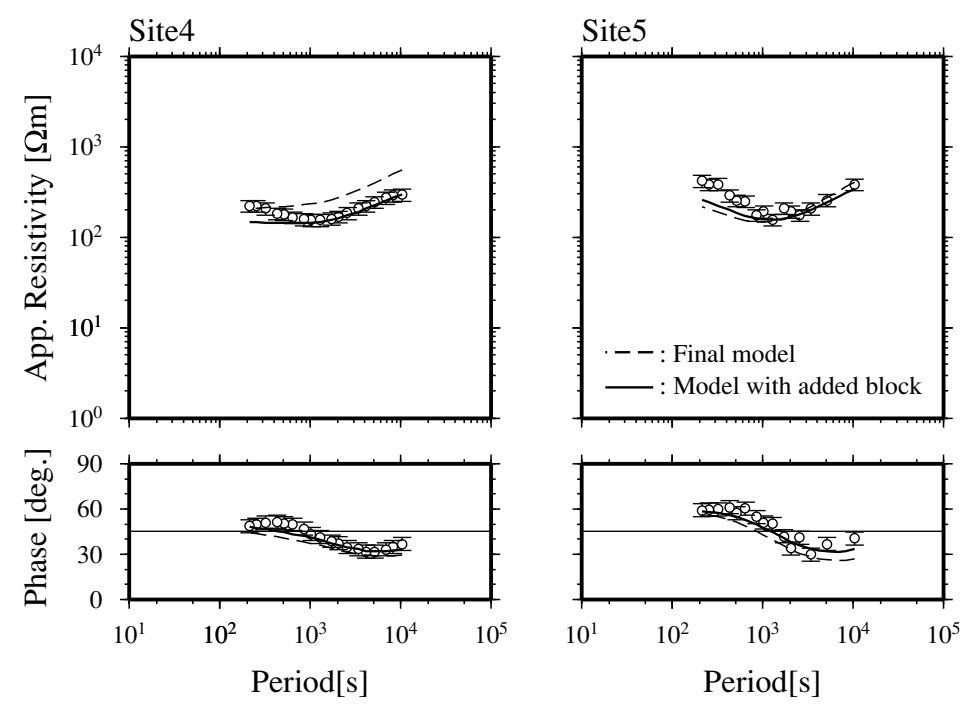

Fig. 10. Comparison of the model responses (dashed lines) obtained from the final model, and the forward-modeled responses (solid lines) derived from a model with two added blocks. The model with an added block was constructed by adding two two-layered blocks (consisting of a resistor and a conductor in each) into the final model (see text for a detailed explanation). Open circles with error bars represent observed values.

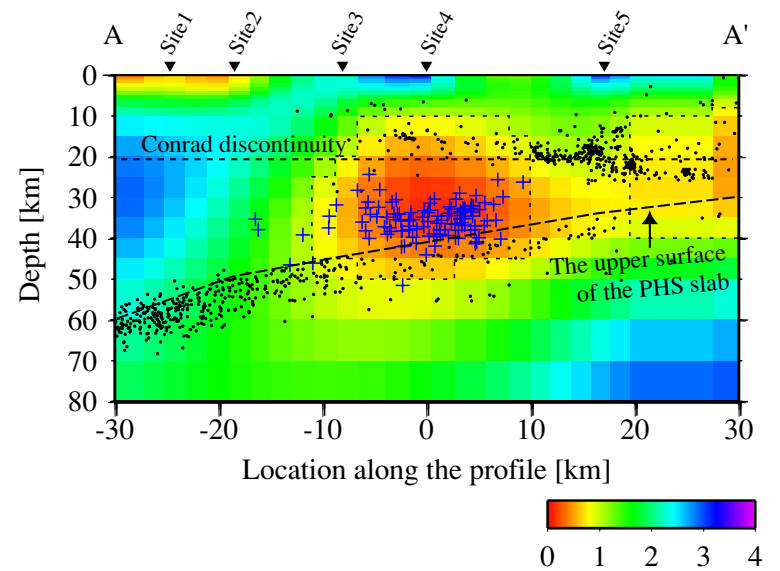

Resistivity $[\log (\Omega \mathrm{m})]$

Fig. 11. 2-D geo-electric cross-section and seismicity along the transect A-A'. Two types of hypocenters are shown here: hypocenters of DLTs (blue 'plus' symbols) and those of regular earthquakes (black dots). Earthquake hypocenters within $10 \mathrm{~km}$ either side of the transect during the period from October 1997 through December 2005 were sourced from the integrated hypocenter database prepared by the Japan Meteorological Agency (Ueno et al., 2002). Site locations are indicated along the top of the figure. Location of the Conrad discontinuity and the upper surface of the PHS slab, which were defined by Yamauchi et al. (2003) based on a receiver function analysis, are indicated by thick and thin dashed lines, respectively.

Meteorological Agency (Ueno et al., 2002). Two types of hypocenters are shown here: the hypocenters of DLTs (blue 'plus' symbols in Fig. 11) and those of regular earthquakes (black dots). It is noteworthy that the hypocenters of DLTs are located in the highly conductive $\mathrm{C} 1$ zone, whereas very few hypocenters are found in this zone. Furthermore, the hypocenters of regular earthquakes are concentrated around the margin of the $\mathrm{C} 1$ zone.

Matsubara et al. (2008) constructed fine-scale 3-D $P$ wave $\left(V_{p}\right)$ and $S$-wave $\left(V_{s}\right)$ velocity structures of the crust and upper mantle beneath the Japan Islands. Figure 12

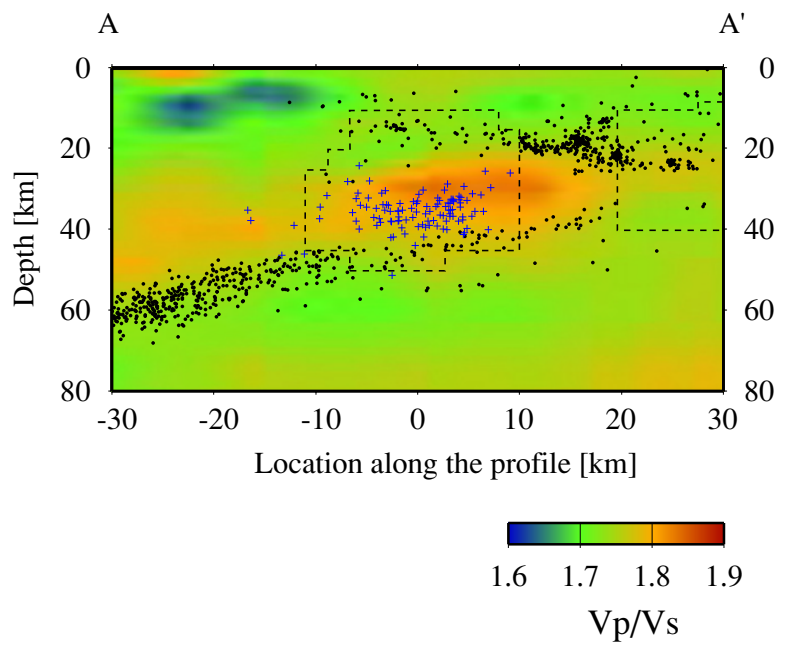

Fig. 12. $V_{p} / V_{s}$ values along the transect $\mathrm{A}-\mathrm{A}$ '. Blue 'plus' symbols and black dots represent the hypocenters of DLTs and regular earthquakes, respectively. The dashed areas represent the locations of highly conductive zones $(\mathrm{C} 1$ and $\mathrm{C} 2)$.

shows a cross-section of the $V_{p} / V_{s}$ value along the transect A- $\mathrm{A}^{\prime}$ based on their structure, along with the hypocenters of regular earthquakes and DLTs. The authors noted that the DLTs occur landward of the high- $V_{p} / V_{s}$ area, as previously reported by Honda and Nakanishi (2003). This feature has also been recognized in western Shikoku (Shelly et al., 2006). A highly conductive zone (C1) corresponds to the high- $V_{p} / V_{s}$ area, although the high $-V_{p} / V_{s}$ area is located in the lower part of the $\mathrm{C} 1$ zone.

We assessed the degree to which the features of the final model, especially those features related to the hypocentral distribution and the high $-V_{p} / V_{s}$ area, are sensitive to the MT data. We constructed representative conductivity test models (Cases 1-4). Cases 1-3 are concerned with the conductivity, basal depth, and upper depth of the highly conductive zone $\mathrm{C} 1$, respectively, and Case 4 is concerned 

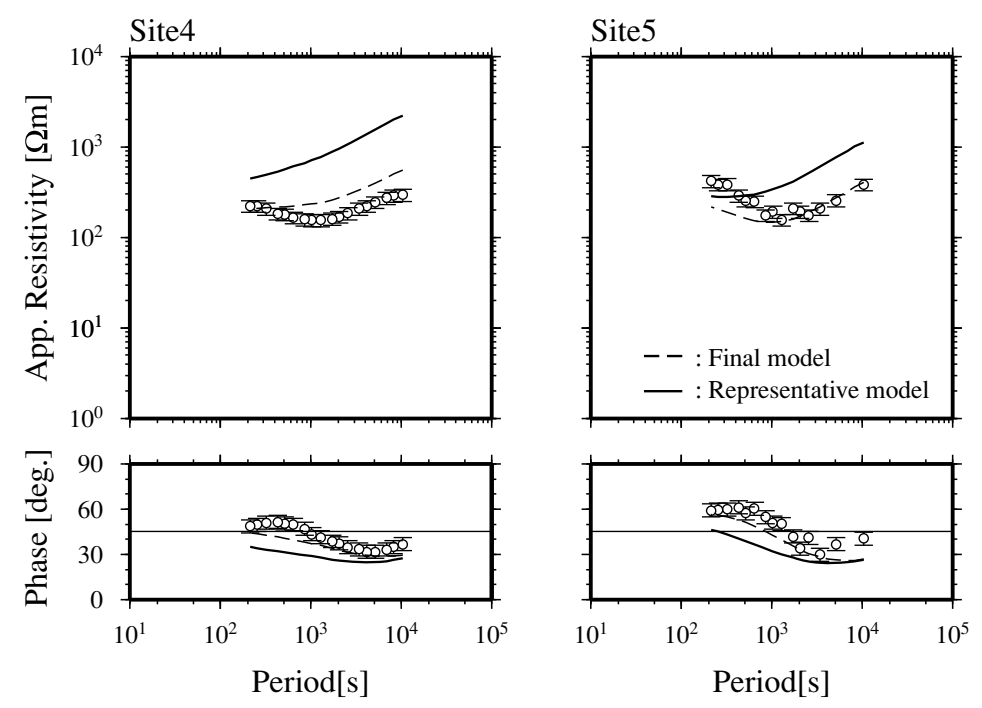

Fig. 13. Comparison of the model responses derived from the final model (dashed lines), and the forward responses from the representative model (Case 1; solid lines). The representative model (Case 1) was constructed by removing the highly conductive zone C1 from the final model. Open circles with error bars represent observed values.

with the conductivity of zone $\mathrm{C} 2$. The forward responses of these representative models were computed and compared with the final model responses and observed data.

In Case 1 , we changed the low resistivity $(<10 \Omega \mathrm{m})$ in zone $\mathrm{C} 1$ to a more resistive value of $10 \Omega \mathrm{m}$, to match the resistivity of surrounding areas. The apparent resistivity and phase values of the representative model (Case 1) show significant differences from values obtained from the final model for all periods at Sites 4 and 5, indicating the existence of a highly conductive region here (Fig. 13). In Case 2, we focused on whether the $\mathrm{C} 1$ zone extends below the upper surface of the PHS slab. The low resistivity value in the conductive zone $(<10 \Omega \mathrm{m})$ below the upper surface was set to $10 \Omega \mathrm{m}$ to match the value in the surrounding area. As both the apparent resistivity and phase value of the representative model (Case 2) show little difference from the final model responses, we cannot confirm whether zone $\mathrm{C} 1$ is restricted to the region above the subcrustal seismic zone.

In Case 3, we changed the upper depth of the highly conductive zone $\mathrm{C} 1$ to match the upper depth of the high- $V_{p} / V_{s}$ area ( $\sim 25 \mathrm{~km}$ depth), and again to match the upper boundary of the DLT hypocenters ( $\sim 30 \mathrm{~km}$ depth). In the latter case, we made another model with a conductor which is completely overlies the tremor zone keeping conductance equal to the zone $\mathrm{C} 1$ (equal conductance model). These three models show similar responses, deviating significantly from those of the final model and observed values at Site 5; the apparent resistivities of the representative models are higher than that of the final model over the entire period range, and the phase value diminishes at the short-period range (Fig. 14). These results indicate that the three representative models are less suitable than the final model, and suggest that the highly conductive zone $\mathrm{C} 1$ extends upward to shallower level than the high- $V_{p} / V_{s}$ area and the area of DLT hypocenters.

In Case 4 , the low resistivity $(<10 \Omega \mathrm{m})$ in zone $\mathrm{C} 2$ was changed to a more resistive value of $10 \Omega \mathrm{m}$. Both the

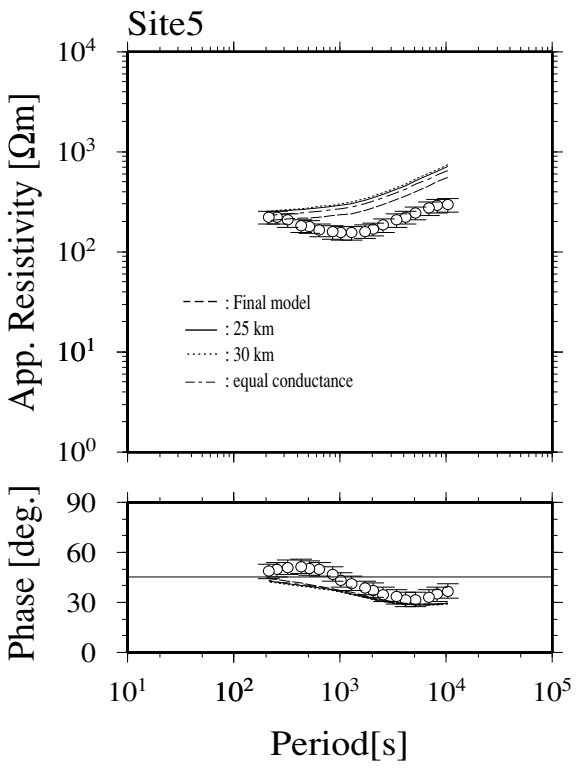

Fig. 14. Comparison of the model responses from the final model (dashed lines) and the forward responses (solid, dotted, and dash-dotted lines) from the representative model (Case 3). The solid, dotted and dash-dotted lines show the responses of the representative model with an upper depth of the highly conductive zone of $25,30 \mathrm{~km}$, and equal conductance model, respectively. Open circles with error bars represent observed values.

apparent resistivity and phase value of the representative model (Case 4) are significantly different from the final model responses for all period ranges at Site 5 (Fig. 15). This result indicates the existence of a highly conductive zone beneath the Pacific.

The heat-flow distribution upon the Kii Peninsula shows a zonal arrangement parallel to the trench, with values increasing to the south (Furukawa et al., 1998). Thus, the highest heat flow measured on land $\left(80 \mathrm{~mW} / \mathrm{m}^{2}\right)$ is observed at the southernmost part of the peninsula. Heat flow above the highly conductive zone $\mathrm{C} 1$ is $\sim 70 \mathrm{~mW} / \mathrm{m}^{2}$, lower than 

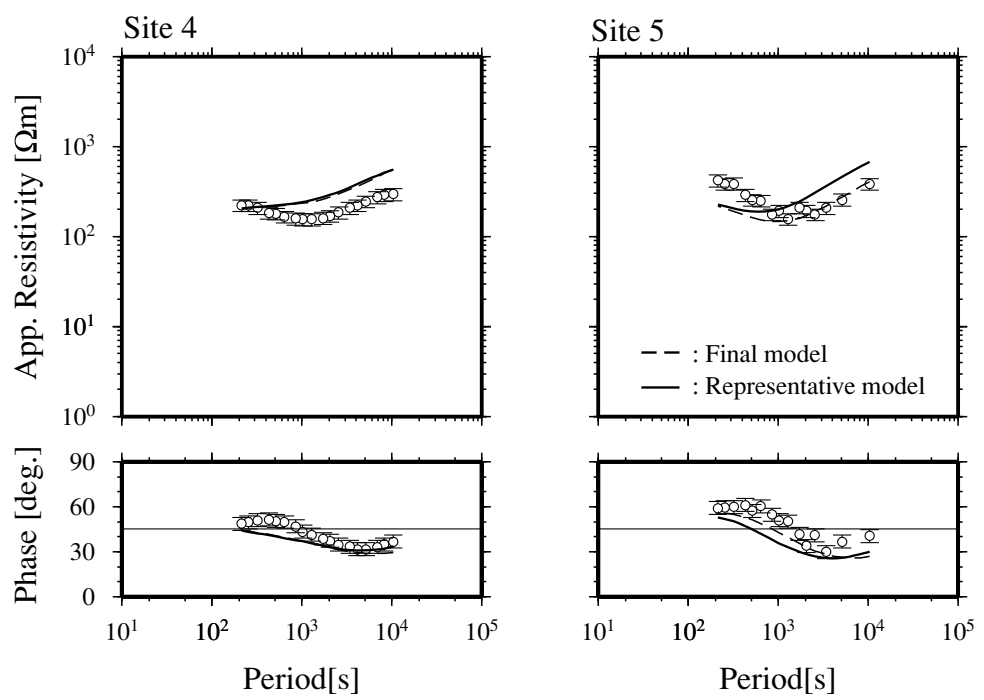

Fig. 15. Comparison of the model responses (dashed lines) derived from the final model and the forward responses (solid lines) derived from the representative model (Case 4). The representative model (Case 4) was constructed by removing the highly conductive zone $\mathrm{C} 2$ from the final model. Open circles with error bars represent observed values.

that in the southernmost part of the transect; it is therefore improbable that the highly conductive zone $\mathrm{C} 1$ represents a region of high temperatures. The presence of fluid can explain the observed distributions of regular earthquakes and DLTs, high $V_{p} / V_{s}$ values, and enhanced conductivity in the highly conductive zone $\mathrm{C} 1$.

In terms of DLTs, Obara (2002) noted that the origin of DLTs located within the highly conductive region is possibly related to the movement of fluid within the subduction zone. This proposal is supported by the results of other studies (e.g. Katsumata and Kamaya, 2003; Seno and Yamasaki, 2003). Furthermore, Matsubara et al. (2008) attributed the origin of DLTs to high pore pressures in the high- $V_{p} / V_{s}$ area, arising from the release of water via dehydration reactions. Shelly et al. (2006) noted that DLTs might result from fluid-enabled shear slip on the plate boundary. In any case, the presence of fluid is an important factor in the generation of DLTs. The fact that the highly conductive zone $\mathrm{C} 1$ is distributed to the shallower depths compared with the hypocentral area of DLTs and the high$V_{p} / V_{s}$ area may indicate the presence of a small amount of fluid in the shallower area of these zones. The fact that the fluid affects electrical resistivity but not seismic velocity in the shallower part of the $\mathrm{C} 1$ may suggest the upward movement or dispersion of fluid following hydro-fracturing.

The shallow, outer boundary of the zone is marked by a shallow seismic zone. Similar structures have been reported from many parts of Japan (e.g. Mitsuhata et al., 2001; Ogawa et al., 2001; Uyeshima et al., 2005). Ogawa et al. (2001) proposed two hypotheses for explaining this coincidence: (1) the coincidence is consistent with the model of Ague et al. (1998), in which earthquake swarms are triggered by the migration of fluid into less permeable crust; and/or (2) the high seismicity is due to the local accumulation of stress near the fluid reservoir.

In addition to seismological aspects, the presence of fluid is supported by previous geochemical studies. Anomalously high ${ }^{3} \mathrm{He} /{ }^{4} \mathrm{He}$ values have been reported from the
Kinki district, contrary to the patterns found in other forearc areas of Japan (Wakita et al., 1987). Matsumoto et al. (2003) documented the distribution of wells with high ${ }^{3} \mathrm{He} /{ }^{4} \mathrm{He}$ values on the Kii Peninsula (Fig. 5), and suggested that upward-moving aqueous fluid derived from the subducting slab carries mantle He from the mantle wedge to the surface.

\section{Conclusions}

The Network-Magnetotelluric (NMT) method is a suitable MT method for investigating deep, large-scale conductivity structure. This method originally made use of earthing facilities installed for telecommunication equipment and metallic transmission cables connecting telephone stations in order to measure voltage differences with a long dipole length of several tens of kilometers; however, this method is no longer feasible because metallic transmission cables have been almost completely replaced with optical fiber cables as part of the modernization of telecommunication networks. To overcome this problem, we developed a modified Network-MT method (modified NMT) using purpose-built electrodes and local metallic lines. This new method brings the added advantages of reduced artificial noise and free arrangement of the dipole.

We applied this modified NMT method to a transect across the central part of the Kii Peninsula, SWJ, and undertook $2-\mathrm{D}$ conductivity modeling along the transect to investigate the detailed features of the deep conductivity structure beneath the peninsula, which was previously unknown.

The shallower part of the final model and the previously proposed model (Fuji-ta et al., 1997) are consistent with each other, indicating in turn the reliability of the final model constructed from data obtained using the newly developed modified NMT method.

The deeper part of the final model is characterized by a large ( $\sim 20 \mathrm{~km}$ wide and 10-60 km deep) and highly conductive $(<10 \Omega \mathrm{m})$ zone in the central part of the peninsula, between the Conrad discontinuity and the upper surface of 
the PHS slab. The hypocenters of deep, low-frequency tremors are located in this highly conductive zone. Few hypocenters of regular earthquakes are located in this zone; instead, they are localized around the zone margins. A high$V_{p} / V_{s}$ area is located in the lower part of the highly conductive zone. Fluids play a role in explaining the occurrence of regular earthquakes, DLTs, high $V_{p} / V_{s}$ values, and enhanced conductivity in the highly conductive zone, as this zone is most likely explained by the presence of fluids.

Acknowledgments. We are grateful to the staff at NTT and NTT Neo-meit Kansai Corporation for their assistance in developing the observation system. The magnetic field data were observed by the Kakioka Magnetic Observatory, Japan Meteorological Agency (JMA) and provided by the World Data Center for Geomagnetism, Kyoto. We used the integrated seismological catalog produced by JMA and the Ministry of Education, Culture, Sports, Science and Technology of Japan; we are grateful to the staff of these organizations. Field assistance was provided by Mr. S. Koyama (University of Tokyo) and Mr. Y. Fujita (Kyoto University). Most of figures were drawn using the GMT software (Wessel and Smith, 1991). This work was supported by a grant (Kiban-B No. 13440133) awarded by the Japan Society for the Promotion of Science and by the Research Center for Urban Safety and Security, Kobe University. This work was also funded by 'The New Program of Research and Observation for Earthquake Prediction' of the Ministry of Education, Culture, Sports, Science and Technology of Japan (MEXT) and the Cooperative Research Program of the Earthquake Research Institute (2001-A-02, 2002-A-02, 2003-A-02).

\section{References}

Ague, J. J., J. Park, and D. M. Rye, Regional metamorphic dehydration and seismic hazard, Geophys. Res. Lett., 25, 4221-4224, 1998.

Archie, G. E., The electrical resistivity log as an aid in determining some reservoir characteristics, Trans. Am. Inst. Mining Eng., 146, 54-62, 1942.

Cagniard, L., Basic theory of the magneto-telluric method of geophysical prospecting, Geophysics, 18, 605-635, 1953.

Chave, A. D. and D. J. Thomson, Some comments on magnetotelluric response function estimation, J. Geophys. Res., 94, 14215-14225, 1989.

Chave, A. D., D. J. Thomson, and M. E. Ander, On the robust estimation of power spectra, coherences, and transfer functions, J. Geophys. Res., 92, 633-648, 1987.

Fischer, G., P. A. Schnegg, M. Peguiron, and B. V. LeQuang, An analytic one-dimensional magnetotelluric inversion scheme, Geophys. J. R. Soc., 67, 257-278, 1981.

Fuji-ta, K., Y. Ogawa, S. Yamaguchi, and K. Yaskawa, Magnetotelluric imaging of the SW Japan forearc-a lost paleoland revealed?, Phys. Earth Planet. Inter., 102, 231-238, 1997.

Furukawa, Y., H. Shinjoe, and S. Nishimura, Heat flow in the southwest Japan arc and its implication for thermal processes under arcs, Geophys. Res. Lett., 25, 1087-1090, 1998.

Geological Survey of Japan, AIST (ed.), Seamless digital geological map of Japan 1: 200,000. May 12, 2007 version, Research Information Database DB084, Geological Survey of Japan, National Institute of Advanced Industrial Science and Technology, 2007.

Glover, P. W. J., P. J. Hole, and J. Pous, A modified Archie's law for two conducting phases, Earth Planet. Sci. Lett., 180, 369-383, 2000.

Groom, R. W. and R. C. Bailey, Decomposition of magnetotelluric impedance tensors in the presence of local three-dimensional galvanic distortion, J. Geophys. Res., 94, 1913-1925, 1989.

Honda, S. and I. Nakanishi, Seismic tomography of the uppermost mantle beneath southwestern Japan: Seismological constraints on modelling subduction and magmatism for the Philippine Sea Slab, Earth Planets Space, 55, 443-462, 2003.

Kariya, K. A. and Shankland, T. J., Electrical conductivity of dry lower crustal rocks, Geophysics, 48, 52-61, 1983.

Kasaya, T., S. Yamaguchi, T. Goto, M. Uyeshima, H. Utada, T. Kagiyama, H. Mikada, and K. Suehiro, Exploration of a deep resistivity structure below the Kii Peninsula, SW Japan, Butsuri-Tansa, 56, 427-437, 2003 (in Japanese with English abstract).

Kasaya, T., T. Goto, H. Mikada, K. Baba, K. Suehiro, and H. Utada, Re- sistivity image of the Philippine Sea Plate around the 1944 Tonankai earthquake zone deduced by Marine and Land MT surveys, Earth Planets Space, 57, 209-213, 2005.

Katsumata, A. and N. Kamaya, Low-frequency continuous tremor around the Moho discontinuity away from volcanoes in the southwest Japan, Geophys. Res. Lett., 30(1), 1020, doi:10.1029/2002GL015981, 2003.

Kaufman, A. A. and G. V. Keller, The magnetotelluric sounding method, Elsevier, Methods in Geochemistry and Geophysics, vol. 15, Elsevier, Amsterdam, 1981.

Ledo, J., P. Queralt, A. Marti, and A. G. Jones, Two-dimensional interpretation of three-dimensional magnetotelluric data: an example of limitations and resolutions, Geophys. J. Int., 150, 127-139, 2002.

Matsubara, M., K. Obara, and K. Kasahara, Three-dimensional P- and Swave velocity structures beneath the Japan Islands obtained by highdensity seismic stations by seismic tomography, Tectonophysics, $\mathbf{4 5 4}$ 86-103, doi:10.1016/j.tecto.2008.04.016, 2008.

Matsumoto, T., T. Kawabata, J. Matsuda, K. Yamamoto, and K. Mimura ${ }^{3} \mathrm{He} /{ }^{4} \mathrm{He}$ ratios in well gases in the Kinki district, SW Japan: surface appearance of slab-derived fluids in a non-volcanic area in Kii Peninsula, Earth Planet. Sci. Lett., 216, 221-230, 2003.

Mitsuhata, Y., Y. Ogawa, M. Mishina, T. Kono, T. Yokokura, and T. Uchida, Electromagnetic heterogeneity of the seismogenic region of 1962 M6.5 Northern Miyagi Earthquake, northeastern Japan, Geophys. Res. Lett., 28, 4371-4374, 2001.

Nakamura, M., H. Watanabe, T. Konomi, S. Kimura, and K. Miura, Characteristic activities of subcrustal earthquakes along the outer zone of southwestern Japan, Ann. Disas. Prev. Res. Inst., Kyoto Univ., 40, B-1, 1997 (in Japanese with English abstract).

Nesbitt, B. E., Electrical resistivities of crustal fluids, J. Geophys. Res., 98, 4301-4310, 1993.

Obara, K., Nonvolcanic deep tremor associated with subduction in southwest Japan, Science, 296, 1679-1681, 2002.

Ogawa, Y., M. Mishina, T. Goto, H. Satoh, N. Oshiman, T. Kasaya, Y. Takahashi, T. Nishitani, S. Sakanaka, M. Uyeshima, Y. Takahashi, Y. Honkura, and M. Matsushima, Magnetotelluric imaging of fluids in intraplate earthquake zones, NE Japan back arc, Geophys. Res. Lett., 28, 3741-3744, 2001.

Poll, H. E., J. T. Weaver, and A. G. Jones, Calculations of voltages for magnetotelluric modelling of a region with near-surface inhomogeneities, Phys. Earth Planet. Inter., 53, 287-297, 1989.

Satoh, H., Y. Nishida, Y. Ogawa, M. Takada, and M. Uyeshima, Crust and upper mantle resistivity structure in the southwestern end of the Kuril Arc as revealed by the joint analysis of conventional MT and network MT data, Earth Planets Space, 53, 829-842, 2001.

Seno, T. and T. Yamasaki, Low-frequency tremors, intraslab and interplate earthquakes in southwest Japan - from a viewpoint of slab dehydration, Geophys. Res. Lett., 30, 2171, doi:10.1029/2003GL018349, 2003.

Shelly, D. R., G. C. Beroza, S. Ide, and S. Nakamula, Low-frequency earthquakes in Shikoku, Japan, and their relationship to episodic tremor and slip, Nature, 442, doi:10.1038/nature04931, 2006.

Shichi, R. and A. Yamamoto (Representatives of the Gravity Research Group in Southwest Japan), Gravity Database of Southwest Japan (CDROM), Bull. Nagoya University Museum, Spec. Rept., No. 9, 2001.

Siripunvaraporn, W., G. Egbert, and M. Uyeshima, Interpretation of twodimensional magnetotelluric transect data with three-dimensional inversion: synthetic examples, Geophys. J. Int., 160, 804-814, 2005.

Uchida, T., Smooth 2-D inversion for magnetotelluric data based on statistical criterion ABIC, J. Geomag. Geoelectr., 45, 841-858, 1993.

Uchida, T. and Y. Ogawa, Development of Fortran code for twodimensional magnetotelluric inversion with smoothness constraint, $\mathrm{Ge}$ ological Survey of Japan Open-File Report, No. 205, 115 pp., 1993.

Uehara, D., C. Kakuta, T. Kudo, K. Umeda, Y. Ogawa, A. Tanase, M. Takeda, A. Chiba, and A. Kikuchi, Geothermal structure of the southern part of the Kii Peninsula estimated from the gravity anomaly and the deep resistivity structure, Zisin Ser. II, 57, 245-255, 2005 (in Japanese with English abstract)

Umeda, K., Y. Ogawa, K. Asamori, and T. Oikawa, Aqueous fluids derived from a subducting slab: Observed high ${ }^{3} \mathrm{He}$ emanation and conductive anomaly in a non-volcanic region, Kii Peninsula southwest Japan, $J$. Volcanol. Geotherm. Res., 149, 47-61, 2006.

Ueno, H., S. Hatakeyama, T. Aketagawa, J. Funasaki, and N. Hamada, Improvement of hypocenter determination procedures in the Japan Meteorological Agency, Q.J. Seismol., 65, 123-134, 2002 (in Japanese with English abstract).

Uyeshima, M., Application of Network MT method to the study of electrical conductivity structure in the central and eastern part of Hokkaido, Dr. Sc. Thesis, Univ. Tokyo, 235 pp., 1990. 
Uyeshima, M., EM monitoring of crustal processes including the use of the Network-MT Observations, Surv. Geophys., 28, 199-237, 2007.

Uyeshima, M., H. Utada, and Y. Nishida, Network-magnetotelluric method and its first results in central and eastern Hokkaido, NE Japan, Geophys. J. Int., 146, 1-19, 2001.

Uyeshima, M., Y. Ogawa, Y. Honkura, S. Koyama, N. Ujihara, T. Mogi, Y. Yamaya, M. Harada, S. Yamaguchi, I. Shiozaki, T. Noguchi, Y. Kuwaba, Y. Tanaka, Y. Mochido, N. Manabe, M. Nishihara, M. Saka, and M. Serizawa, Resistivity imaging across the source region of the 2004 Mid-Niigata Prefecture earthquake (M6.8), central Japan, Earth Planets Space, 57, 441-446, 2005.

Vozoff, K., The Magnetotelluric Method, in Investigations in geophysics No.3 volume II, edited by M. N. Nabighian, pp. 972, Society of Exploration Geophysics, 1991.

Wakita, H., Y. Sano, and M. Mizoue, High ${ }^{3} \mathrm{He}$ emanation and seismic swarms observed in a nonvolcanic, forearc region, J. Geophys. Res., 92 , 12539-12546, 1987.

Wannamaker, P. E., G. W. Hohmann, and S. H. Ward, Magnetotelluric responses of three-dimensional bodies in layered earths, Geophysics, 49, 1517-1533, 1984.

Wessel, P. and W. H. F. Smith, Free software helps map and display data, Eos Trans. AGU, 72, 441, 1991.

Yamaguchi, S., Y. Kobayashi, N. Oshiman, K. Tanimoto, H. Murakami, I. Shiozaki, M. Uyeshima, H. Utada, and N. Sumitomo, Preliminary report on regional resistivity variation inferred from the Network MT investigation in the Shikoku district, southwestern Japan, Earth Planets Space, 51, 193-203, 1999.

Yamauchi, M., K. Hirahara, and T. Shibutani, High resolution receiver function imaging of the seismic velocity discontinuities in the crust and the uppermost mantle beneath southwest Japan, Earth Planets Space, 55, 59-64, 2003.

S. Yamaguchi (e-mail: yanchi@kobe-u.ac.jp), M. Uyeshima, H. Murakami, S. Sutoh, D. Tanigawa, T. Ogawa, N. Oshiman, R. Yoshimura, K. Aizawa, I. Shiozaki, and T. Kasaya 